Thus the effects of MCT-induced pulmonary hypertension on responsiveness of pulmonary artery to vasodilator drugs with different mechanisms of action varied. The loss in potency of the nitrovasodilator, NP, is unlikely to be due to a reduced relaxant effect of cyclic GMP because there was no loss in potency for AP (which also acts through cyclic GMP albeit via membrane rather than soluble guanylate cyclase). It is not yet known whether the increase in vasodilator potency seen for PIN in this model of pulmonary hypertension will be shared by other potassium channel opening drugs. It was not seen for NIC, a drug which like pinacidil can open membrane potassium channels but this may be because any increase in potency associated with this mechanism could be overridden by a decrease in potency associated with its additional properties resembling those of the nitrovasodilators.

The PA/AO selectivity seen for PIN in vessels from rats with pulmonary hypertension induced by MCT but not in controls, suggests that it may be worthwhile to investigate pinacidil, and possibly other potassium channel opening drugs, in patients with pulmonary hypertension where other drugs have proved inadequate.

P.we.106

\title{
The central and regional cardiovascular responses to intravenous administra in of the potassium channel opener EMD 52692
}

\author{
Duncker, D.J.G.M., Sassen, L.M.A., Gho, B.C. and Verdouw, P.D. \\ Laboratory for Experimental Cardiology, Thoraxcentre, Erasmus University Rotierdam, P.O. Box 1738. \\ 3000 DR Rotterdam, The Netherlands
}

The present study was conducted to investigate the systemic and regional haemodynamic effects of the newly synthesized potassium channel opener EMD $52692(n=7)$ or its solvent $(n=7)$ after intravenous auministration in anaesthetized pigs. Infusion of thes soivent did not affect systemic haemodynamics (baseline values ior heart rate, mean arterial blood pressure, cardiac output, systemic vascular resistance, left ventricular end diastolic blood pressure and left ventricular $\mathrm{dP} / \mathrm{dt}_{\max }$ were $99 \pm 6$ beats $\mathrm{min}^{-1}, 89 \pm 5 \mathrm{mmHg}, 2.8 \pm 0.21 \mathrm{~min}^{-1}, 34 \pm 4 \mathrm{mmHg} \cdot \mathrm{min} 1^{-1}, 6 \pm 1$ $\mathrm{mmHg}$ and $2670 \pm 170 \mathrm{mmHg} \mathrm{s}^{-1}$, respectively). Consecutive $10 \mathrm{~min}$ intravenous infusions of EMD $52692(0.15,0.30$, $0.60,1.20 \mu \mathrm{g} \mathrm{kg}^{-1} \mathrm{~min}^{-1}$ ) caused a dose-dependent decrease in mean arterial blood pressure from $90 \pm 3$ to $44 \pm 4$ $\mathrm{mmHg}$. This was entirely due to peripheral vasodilatation (decrease in systemic vascular resistance from $31 \pm 3$

Table 1

Effec: of intravenous infusions of EMD $52692\left(\mu \mathrm{g} \mathrm{kg} \mathrm{gin}^{-1}\right.$, E) or equal volumes of its solvent (S) on regional vascular conductances ( $\mathrm{ml} \mathrm{min} 100 \mathrm{~g}^{-1} \mathrm{rumHg}^{-1}$ ).

\begin{tabular}{|c|c|c|c|c|c|c|}
\hline & Baseline & 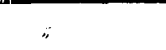 & 0.15 & 0.30 & 0.60 & 1.2 \\
\hline \multirow[t]{2}{*}{ Subepicardium } & $\mathbf{S}$ & $162 \pm 33$ & $169 \pm 38$ & $156 \pm 16$ & $151 \pm 11$ & $158 \pm 9$ \\
\hline & $\mathbf{E}$ & $173 \pm 17$ & $185 \pm 15$ & $248 \pm 19 *$ & $369 \pm 37$ & $450 \pm 40 *$ \\
\hline \multirow[t]{2}{*}{ Subendocardium } & $\mathbf{S}$ & $203 \pm 35$ & $198 \pm 38$ & $196 \pm 17$ & $196 \pm 15$ & $194 \pm 16$ \\
\hline & $\mathbf{E}$ & $209 \pm 36$ & $406 \pm 20$ & $507 \pm 47$ & $523 \pm 47$ & $412 \pm 44$ \\
\hline \multirow[t]{2}{*}{ Total brain } & $\mathbf{S}$ & $37 \pm 5$ & $41 \pm 3$ & $36 \pm 3$ & $36 \pm 3$ & $35 \pm 3$ \\
\hline & $\mathbf{E}$ & $37 \pm 2$ & $42 \pm 3$ & $67 \pm 6$ & $129 \pm 7$ & $163 \pm 12$ * \\
\hline M. pectoralis & $S$ & $2.5 \pm 0.7$ & $2.3 \pm 0.7$ & $2.2 \pm 0.4$ & $1.7 \pm 0.2$ & $\begin{array}{l}1.8 \pm 0.3 \\
4.8+0.8\end{array}$ \\
\hline \multirow[t]{2}{*}{ Kidneys } & $\begin{array}{l}\mathbf{E} \\
\mathbf{S}\end{array}$ & $289 \pm 31$ & $314 \pm 25$ & $295 \pm 34$ & $279 \pm 31$ & $267 \pm 17$ \\
\hline & $\mathbf{E}$ & $278 \pm 23$ & $274 \pm 17$ & $335 \pm 33$ & $388 \pm 33$ & $319 \pm 34$ \\
\hline \multirow[t]{2}{*}{ Adrenals } & $\mathbf{S}$ & $153 \pm 22$ & $172 \pm 14$ & $164 \pm 11$ & $160 \pm 14$ & $167 \pm 19$ \\
\hline & $\mathbf{E}$ & $204 \pm 32$ & $270 \pm 30$ & $516 \pm 36$ & $583 \pm 42 *$ & $545 \pm 44$ \\
\hline Skin & S & $\begin{array}{l}2.2 \pm 0.7 \\
2.7 \pm 0.5\end{array}$ & $\begin{array}{l}2.2 \pm 1.2 \\
3.3 \pm 0.7\end{array}$ & $\begin{array}{l}1.8 \pm 0.5 \\
3.6 \pm 0.9\end{array}$ & $\begin{array}{l}2.3 \pm 0.8 \\
5.1 \pm 0.7\end{array}$ & $\begin{array}{l}2.8 \pm 1.3 \\
5.8 \pm 0.6\end{array}$ \\
\hline
\end{tabular}

data are means \pm sem; " EMD 52692-induced changes versus baseline are significantly different from solvent-induced changes 
mmHg.min $1^{-1}$ to $15 \pm 2 \mathrm{mmHg} \cdot \min \mathrm{l}^{-1}$ ), since cardiac output (baseline $3.0 \pm 0.21 \mathrm{~min}^{-1}$ ) did not change. The EM 52692-induced increase in heart rate from $103 \pm 7$ beats $\min ^{-1}$ to $151 \pm 13$ beats $\min ^{-1}$ may be due to reflex activation of the sympathetic nervous system. Left ventricular end diastolic pressure dose-dependently decreased from $6 \pm 1 \mathrm{mmHg}$ to $3 \pm 1 \mathrm{mmHg}$ causing a fall in stroke volume from $30 \pm 2 \mathrm{ml}$ to $21 \pm 2 \mathrm{ml}(\mathrm{P}<0.05)$. Table 1 shows that vasodilatation was not the same for all organs and that in particular the vascular conductance of the cerebral vessels increased. In spite of the $20 \%$ decrease in myocardial oxygen consumption there was an increase in left ventricular blood flow, which was however only confined to the subepicardial layers. It is concluded that EM 52692 is a very potent vasodilator, especially of the cerebral vasculature.

P.we.107

\title{
Dual mechanisms of relaxation by nicorandil through cyclic GMP and membrane hyperpolarization
}

\author{
Holzmann, S., Braida, C., Pöch, G. and Kukovetz, W.R. \\ Institute of Pharmacodynamics and Toxicology, University of Graz, Univ. Pl. 2, A-8010 Graz, Austria
}

In addition to previous results from our laboratory showing that nicorandil relaxed vascular smooth muscle by increasing cyclic GMP (cGMP) levels, it was found that it also activated K-channels, an effect which also leads to relaxation. In the present study it was attempted to differentiate quantitatively between these two effects in isolated bovine coronary arterial strips with simult seous isotonic measurement of length and RIA-determination of cGMP. When the strips were contracted by the thromboxan analogue $U 46619(1 \mu \mathrm{M})$ in the presence of $10 \mu \mathrm{M}$ methylene blue nicorandil produced $30-50 \%$ relaxation without significant changes in cGMP.

When in $U \mathbf{4 6 6 1 9}$ contracted strips the hyperpolarizing effect of nicorandil was suppressed by raising extracellular $\mathrm{K}^{+}$to the 30 -fold control value $(80 \mathrm{mM})$, or by addition of $10 \mathrm{mM} \mathrm{Ba}^{++}$, nicorandil only caused $52 \%$ and $40 \%$ relaxation, respectively, whereas cGMP-rises were not significantly suppressed.

Quantitative separation of both mechanisms of relaxation by nicorandil was further achieved through calculation of the cGMP mediated component from a correlation between rises in CGMP and percent relaxation as produced by nicorandil under conditions of inhibited hyperpolarization, i.e. in strips contracted with $1 \mu \mathrm{M} \mathrm{U} 46619$ or $10 \times \mathrm{K}^{+}$ and exposed to either 30 -fold $\mathrm{K}^{+}(80 \mathrm{mM})$ or $10 \mathrm{mM} \mathrm{Ba}^{++}$. Under both conditions similar correlations between cGMP and relaxation were obtained.

The cGMP mediated part was $20 \%$ at low concentrations of $40-100 \mu \mathrm{M}$ to $40 \%$ at high concentrations of $0.47-1.4$ $\mathrm{mM}$ of the total relaxation produced by nicorandil in $U 46619$ contracted strips. Since $U \mathbf{4 6 6 1 9}$ in addition to its contractile effect antagonized the relaxation by nicorandil to some extent without changing cGMP, the correlation when corrected for this effect yielded a participation of cGMP in the overall relaxant response of $40 \%$ at low concentrations to $85 \%$ at high concentrations of nicorandil.

The existence of two independent effects was also demonstrated by calculating the dose response curves for independent and for additive effects of the cGMP-activators nitroglycerin, nitroprusside- $\mathrm{Na}$, nitrosoglutathion and SIN-1 in the presence of one concentration of 20 or $50 \mu \mathrm{M}$ nicorandil. In all of these cases the independence of the effect of added nicorandil from the eifect of the respective nitrocompound could be demonstrated.

These results indicate that nicorandil at low concentrations mainly relaxes by hyperpolarization whereas higher concentrations mainly relax through cGMP. 